\title{
PENGARUH MODEL COOPERATIVE LEARNING TIPE TALKING STICK TERHADAP PENINGKATAN PENGETAHUAN BAHAYA MEROKOK PADA SISWA SMP
}

\author{
Erma Wahyu Mashfufa', Gusmery Fathoni² \\ Program Studi IImu Keperawatan, Fakultas IImu Kesehatan, Universitas Muhammadiyah Malang \\ JI. Bendungan Sutami 188A Malang 65145 \\ E-mail : ermawahyumashfufa@gmail.com
}

\begin{abstract}
Health education is an important role as preventive action, especially in adolescents about the dangers of smoking. Using the cooperative model type talking stick is expected to increase the knowledge of the dangers of smoking. Cooperative learning type talking stick model is a learning strategy with a number of students as a small group member, in the completion of group tasks each student group members should work together and help each other to understand the material. The purpose of this study is to determine the effect of cooperative learning type of talking stick to increase the knowledge of the danger of smoking on the students. The research design used was preexperimental with one group pre-test and post-test design. The subjects of this study were grade VII students who smoked as many as 43 students were taken with total sampling method, and data analysis uses Wilcoxon Test. Wilcoxon test results with the SPSS program, obtained the value of knowledge variables, probability value $=0,000$ and the value of $\alpha=0.05$ so that the value of $p<\alpha$ and sig value. (0.000) $<0,05$ can be deduced There is influence of cooperative learning type of talking stick model to increase knowledge of smoking hazard to Junior High School student.
\end{abstract}

Keywords : Model of cooperative learning type talking stick, knowledge.

Abstrak : Pendidikan kesehatan menjadi peran penting sebagai tindakan preventif khususnya pada remaja tentang bahaya merokok. Menggunakan model cooperative learning tipe talking stick diharapkan mampu meningkatkan pengetahuan bahaya merokok. Model cooperative learning tipe talking stick merupakan strategi belajar dengan melibatkan sejumlah siswa sebagai anggota kelompok kecil, dalam penyelesaian tugas kelompoknya setiap siswa anggota kelompok harus saling bekerja sama dan saling membantu untuk memahami materi. Tujuan penelitian ini adalah untuk mengetahui pengaruh cooperative learning tipe talking stick terhadap peningkatan pengetahuan bahaya merokok pada siswa SMP. Desain penelitian yang digunakan adalah pre-experimental dengan one group pretes dan post-test design. Subjek penelitian ini adalah siswa kelas VII yang merokok sebanyak 43 siswa diambil dengan metode total sampling, dan analisis data menggunakan Uji Wilcoxon. Hasil Uji Wilcoxon dengan program SPSS, diperoleh nilai variabel pengetahuan, nilai probabilitas $=0,000$ dan nilai $\alpha=0,05$ sehingga nilai $p<\alpha$ dan nilai sig. $(0,000)<0,05$ dapat ditarik kesimpulan ada pengaruh model cooperative learning tipe talking stick terhadap peningkatan pengetahuan siswa SMP.

Kata Kunci : Model cooperative learning tipe talking stick, pengetahuan.

\section{PENDAHULUAN}

Merokok merupakan perilaku yang merugikan kesehatan, menjadi salah satu penyebab kematian. Kondisi yang sangat dramatis saat ini pengkonsumsi rokok sudah di mulai dari anak-anak usia sekolah. Di Indonesia sendiri perilaku merokok sudah banyak ditemukan pada anak-anak tingkat sekolah menengah pertama, salah satu penyebabnya kurang pengetahuan mengenai bahaya merokok, lingkungan yang mendukung anak untuk merokok dan kondisi sosial ekonomi (Kemenkes, 2018).

Menurut data WHO Jumlah perokok di dunia pada tahun 2009 mencapai 1,3 milyar orang. Data kemenkes menunjukkan bahwa prevalensi remaja usia 16-19 tahun yang merokok meningkat 3 kali lipat dari 7,1\% di tahun 1995 menjadi 20,5\% pada tahun 2014, terdapat lebih dari 50 juta orang di Indonesia yang membelanjakan uangnya secara rutin hanya untuk membeli rokok. Terhitung dalam sehari rata-rata penduduk Indonesia menghabiskan 12 batang rokok (Kemenkes, 2018).

Kondisi yang ada saat ini merokok sudah menjadi trend dan sebagai tanda modernisasi. Menjadi tugas kita bersama untuk menjaga generasi muda dari bahaya merokok dan memprioritaskan hidup sehat untuk mereka. Melalui pendidikan kesehatan bertujuan untuk meningkatkan pengetahuan remaja dalam bidang kesehatan tetapi juga membantu merubah perilaku ke arah yang lebih baik. Remaja merupakan masa transisi 
antara masa anak dan dewasa. Perkembangan kepribadian pada masa ini tidak dipengaruhi oleh orang tua dan lingkungan keluarga saja, tetapi juga lingkungan sekolah dan teman-teman pergaulan di luar sekolah. Usia sekolah merupakan masa dimana anak belajar. Dalam psikologi perkembangan pubertas (10-14 tahun), usia tersebut termasuk dalam masa remaja awal yaitu antara 12-15 tahunn (Desmita, 2014). Pendidikan kesehatan telah menjadi salah satu peran yang sangat penting bagi perawat di semua lahan asuhan keperawatan baik di klinik maupun di komunitas (Negara, 2013).

Belajar akif merupakan salah satu model pembelajaran sebagai sarana pendidikan kesehatan yang menggunakan prinsip konstruktivisme. Beberapa model pembelajaran yang didasarkan pada konstruktivisme adalah cooperative learning (Baharudin, 2010). Metode mooperative learning dapat meningkatkan pengetahuan siswa karena model cooperative learning mengajarkan sesuatu secara bersama-sama, yaitu dengan saling membantu antara satu sama lain sebagai sebuah tim. Jadi, model cooperative learning dapat diartikan sebagai belajar bersama-sama, saling membantu antara satu dengan yang lain, dan memastikan bahwa setiap orang dalam kelompok mampu mencapai tujuan atau menyelesaikan tugas yang telah ditentukan, dengan model cooperative learning, siswa dilatih untuk bekerja sama dengan temanya secara sinergis, integral, dan kombinatif. Selain itu, para siswa juga diajak menghindari sifat egois, individualis, serta kompetisi tidak sehat sedini mungkin agar masing-masing tidak mementingkan kepentingan pribadi dan kelompoknya (Asmani, 2016). Tipe talking stick ini sangat sederhana dan cukup mudah untuk dipraktekkan, khususnya pada siswa SD, SMP, dan SMA / SMK, selain sebagai metode agar siswa mau berpendapat, tapi juga untuk melatih siswa berani berbicara, dengan model pembelajaran ini suasana kelas bisa terlihat lebih hidup dan tidak monoton (Kurniasih \& Sani, 2015).

\section{METODE PENELITIAN}

Desain penelitian ini menggunakan metode pra-experimental dengan one group pre-test dan post-test design untuk mengetahui perubahan pengetahuan siswa, populasi dalam penelitian ini adalah seluruh siswa kelas VII SMP Nurul Jadid Paiton yang berjumlah 115 orang. Teknik sampling yang digunakan dalam penelitian ini adalah total sampling sebanyak 43 responden. Pelaksanaan pre-test tanggal 02 Desember 2017, dengan memberikan pendidikan kesehatan dengan model cooperative learning tipe talking stick tentang bahaya merokok, pelaksaan post-test tanggal 23 Desember 2017. Variabel independen dalam penelitian ini adalah pembelajaran cooperative learning tipe talking stick. Variabel dependen dalam penelitian ini adalah peningkatan pengetahuan bahaya merokok pada siswa SMP Nurul Jadid Paiton Kabupaten Probolinggo, Instrumen yang digunakan untuk penelitian ini adalah kuesioner.

\section{HASIL PENELITIAN}

Tabel 1. Pengaruh Model Cooperative Learning tipe Talking Stick Terhadap Peningkatan Pengetahuan Bahaya Merokok

\begin{tabular}{cccccc}
\hline Variabel & Mean & $\begin{array}{c}\text { Standar } \\
\text { Deviasi }\end{array}$ & $\begin{array}{c}\text { Nilai } \\
\text { Min }\end{array}$ & $\begin{array}{c}\text { Nilai } \\
\text { Max }\end{array}$ & $\begin{array}{c}\mathbf{P} \\
\text { value }\end{array}$ \\
\hline $\begin{array}{c}\text { Pretest Pengetahuan } \\
\text { Terhadap Bahaya } \\
\text { Merokok }\end{array}$ & 65,23 & 13,27 & 20,00 & 90,00 & \\
$\begin{array}{c}\text { Postest Pengetahuan } \\
\text { Terhadap Bahaya } \\
\text { Merokok }\end{array}$ & 80,81 & 15,23 & 40.00 & 100 & 0,000 \\
\hline
\end{tabular}

Berdasarkan tabel 1 nilai rata-rata sampel untuk pengetahuan bahaya merokok sebelum diberikan model cooperative learning tipe talking stick adalah 65,23. Simpangan baku atau standar deviasi sebesar 13,27 . Nilai minimum dan maksimum pengetahuan bahaya merokok sebelum diberikan model cooperative learning tipe talking stick adalah 20,00 dan 90,00, sedangkan nilai ratarata sampel pengetahuan bahaya merokok sesudah diberikan model cooperative learning tipe talking stick adalah 80,81. Simpangan baku atau standar deviasi sebesar 15,23. Nilai minimum dan maksimum pengetahuan bahaya merokok sesudah diberikan model cooperative learning tipe talking stick adalah 40,00 dan 100,00. 
Nilai probabilitas $=0,000$ dan nilai a 0,05 sehingga nilai $P<\alpha$ dan nilai sig. $(0,000)<0,05$. Dapat ditarik kesimpulan $\mathrm{Ho}$ ditolak dan $\mathrm{H} 1$ diterima. Artinya "Ada pengaruh model cooperative learning tipe talking stick terhadap peningkatan pengetahuan bahaya merokok pada siswa SMP Nurul Jadid Paiton".

Tabel 2. Pengetahuan Bahaya Merokok Sebelum Dan Sesudah Diberikan Model Cooperative Learning tipe Talking Stick

\begin{tabular}{ccc}
$\begin{array}{c}\text { Tingkat } \\
\text { Pengetahuan }\end{array}$ & $\begin{array}{c}\text { Jumlah } \\
\text { (orang) }\end{array}$ & $\begin{array}{c}\text { Persentase } \\
\text { (\%) }\end{array}$ \\
Menurun & 0 & 0,00 \\
Tetap & 16 & 37,21 \\
Meningkat & 27 & 62,79 \\
\hline Total & 43 & 100 \\
\hline
\end{tabular}

Berdasarkan tabel 2 perubahan pengetahuan sebelum dan sesudah diberikan model cooperative learning tipe talking stick mengalami peningkatan pengetahuan yaitu sebanyak 27 orang $(62,79 \%)$, mempunyai pengetahuan tetap sebanyak 16 orang $(37,21 \%)$, dan tidak ada responden yang mengalami penurunan tingkat pengetahuan.

\section{PEMBAHASAN}

\section{Pengetahuan Responden Sebelum Diberikan Model Cooperative Learning Tipe Talking Stick.}

Berdasarkan analisis data didapatkan hasil sebelum diberikan model cooperative learning tipe talking stick memiliki tingkat pengetahuan tergolong rendah hal ini disebabkan karena pengetahuan responden sebelum diberikan model cooperative learning tipe talking stick di pengaruhi oleh beberapa faktor seperti usia, tingkat pendidikan dan pengetahuan, lingkungan, tidak pernah mendapat informasi sebelumnya dan sosial ekonomi. Menurut Notoatmodjo (2012) Pengetahuan merupakan hasil dari tahu, dan ini terjadi setelah orang melakukan pengindraan terhadap suatu objek tertentu. Pengindraan terjadi melalui pancaindra manusia, yakni indra penglihatan, pendengaran, penciuman, rasa, dan raba. Sebagian pengindraan pada manusia diperoleh melalui mata dan telinga. Pengetahuan dapat diperoleh seseorang secara alami atau di intervensi baik langsung maupun tidak langsung.

\section{Pengetahuan Responden Sesudah Diberikan Model Cooperative Learning Tipe Talking Stick.}

\section{KESIMPULAN}

Berdasarkan hasil penelitian model cooperative learning tipe talking stick berpengaruh terhadap peningkatan
Berdasarkan analisis data didapatkan hasil peningkatan pengetahuan responden sesudah diberikan model cooperative learning tipe talking stick mengalami peningkatan pengetahuan, Peningkatan pengetahuan dan pemahaman yang diterima oleh responden menunjukkan bahwa pendidikan kesehatan dengan model cooperative learning tipe talking stik yang di berikan pada umur remaja sangat cepat diterima dan dipahami. Sebagaimana pernyataan teori Perry \& Potter (2005) bahwa perkembangan kognitif mencapai puncaknya pada umur remaja, remaja mengolah informasi yang baru diterimanya dengan sangat cepat sehingga remaja mudah memahami atau mengerti materi yang baru disampaikan.

Notoatmodjo (2012) menyatakan bahwa perubahan perilaku (termasuk dalamnya pengetahuan) seseorang dapat terjadi melalui proses belajar. Teori ini mendukung penelitian bahwa dengan adanya pendidikan kesehatan dengan model cooperative learning tipe talking stick dapat mempengaruhi tingkat pengatahuan responden yang harapannya dapat merubah perilaku responden. Menjadi penelitian dasar untuk mewujudkan Indonesia bebas asap rokok dan menurunkan angka kesakitan akibat merokok.

pengetahuan bahaya merokok pada siswa SMP Nurul Jadid Paiton. 


\section{DAFTAR PUSTAKA}

Asmani, J.M. (2016). Tips Efektif cooperative learning. Yogyakarta: DIVA Press.

Azwar, S. (2016). Penyusunan Skala Psikologi. Yogyakarta: Pustaka Belajar.

Baharudin. (2010). Teori Belajar dan Pembelajaran.Yogyakarta: Ar-Ruzz Media.

Desmita (2006).Psikologi Perkembangan. Bandung: PT Remaja Rosdakarya,

Kementrian Kesehatan RI. (2011). Riset Kesehatan Dasar Badan Penelitian dan Pengembangan Kesehatan. Jakarta.

Kementrian Kesehatan RI. (2018). Riset Kesehatan Dasar Badan Penelitian dan Pengembangan Kesehatan. Jakarta.

Kharis, L. (2014). Pengaruh Model Pembelajaran Cooperative Learning tipe Talking Stick Untuk Meningkatkan Hasil Belajar Siswa Pada Mata Pelajaran Teknik Informatika di SMK \& Surabaya. c Skripsi . Fakultas Teknik. Universitas Negeri Surabaya. Skripsi . Fakultas Teknik. Universitas Negeri Surabaya.
Kurniasih, I., \& Sani, B. (2015). Ragam Pengembangan Model Pembelajaran. Jakarta: Kata Pena.

Negara, M.P. (2013). Pengaruh Action learning Terhadap Pengetahuan dan Sikap Remaja tentang HIVIAIDS dan Klinik Voluntary Counseling and Testing (VCT) di SMK Perikanan dan Kelautan Puger Kabupaten Jember. Skripsi. Fakultas IImu Keperawatan Universitas Jember.

Notoatmodjo, S. (2012). Metodologi Penelitian Kesehatan. Jakarta:Rineka Cipta.

Potter, P.A., Perry, A.G. (2009). Fundamental of Nursing Buku 1, Edisi 7. Jakarta: Salemba Medika.

WHO. (2009). Dampak Tembakau dan Pengendaliannya di Indonesia. Lembar Fakta Untuk Masukan Kebijakan. Jakarta. 